\title{
Financial Stability Governance and Communication
}

\author{
Londono, Juan M. ${ }^{\text {a }}$; Claessens, Stijn ${ }^{\text {b }}$; Correa, Ricardo ${ }^{\text {a }}$; and Mislang, Nathan ${ }^{\text {a }}$ \\ ${ }^{\mathrm{a}}$ Federal Reserve Board ${ }^{\mathrm{b}}$ Bank of International Settlements
}

\begin{abstract}
We investigate how differences in governance frameworks across central banks explain their financial stability communication strategies and the effect of these strategies on the evolution of each country's financial cycle. To do so, we propose a simple conceptual framework that explains how central banks conduct their communication strategy, which eventually affects the evolution of financial conditions. To empirically validate our framework, we use a database with the financial stability governance characteristics of 24 central banks and the sentiment conveyed in the financial stability reports published by these central banks. We find that, after observing a deterioration of financial conditions, central banks participating in interagency financial stability committees or with an oversight role transmit a calmer message than banks without these characteristics. We also find that the effect of communication on the evolution of the financial cycle depends on each central bank's governance framework. In particular, communication by central banks participating in an interagency financial stability committee or with a financial supervisory role has an alleviating effect on the deterioration of financial conditions.
\end{abstract}

Keywords: Financial stability, Central bank communications, Governance, Text analysis. 